\title{
Multiresidue Analysis of 86 Pesticides Using Gas Chromatography Mass Spectrometry: II-Nonleafy Vegetables
}

\author{
M. H. EL-Saeid, ${ }^{1}$ and M. T. Selim ${ }^{2}$ \\ ${ }^{1}$ Soil Science Department, College of Food and Agricultural Sciences, King Saud University, P.O. Box 2460, Riyadh 11451, Saudi Arabia \\ ${ }^{2}$ Pesticide Residue Analysis Laboratory and Al-Tamer Vegetables Market, Riyadh Development Company, Al-Azizea, P.O. Box 7442, \\ Riyadh 11462, Saudi Arabia
}

Correspondence should be addressed to M. H. EL-Saeid; elsaeidm@ksu.edu.sa

Received 20 June 2012; Revised 18 July 2012; Accepted 19 July 2012

Academic Editor: Michele Del Carlo

Copyright (C) 2013 M. H. EL-Saeid and M. T. Selim. This is an open access article distributed under the Creative Commons Attribution License, which permits unrestricted use, distribution, and reproduction in any medium, provided the original work is properly cited.

\begin{abstract}
A total of 1057 samples of fresh vegetables from import and domestic production were analyzed (cold pepper, egg plant, carrot, cucumber, potato, hot pepper, cultivation tomato, squash, beans, okra, onions, cauliflower, and green house tomato). The aim of this study was to investigate pesticide residues in market foods in Riyadh, which have been collected from Riyadh Development Company (Al-Tamer Vegetables Market). Pesticide residues were determined by gas chromatography with mass selective detector (GC-MSD). A multiresidue method was developed and described for simultaneous determination of 86 pesticides commonly used in crop protection. This method used to determine 86 pesticide residues with a broad range of physicochemical properties in fresh vegetables related to organophosphorus (OPP), organochlorines (OCP), pyrethroids, and carbamates mainly used in agriculture. Sample extract was cleaned up by using AOAC method. Pesticide residues above the maximum residue limits (MRL) were detected in $15.89 \%$ of the total samples (168 from 1057 samples), but $83.90 \%$ of the total samples ( 887 from 1057 samples) has no residues or contained pesticide residues at or below MRL. The detected and most frequently found pesticide residues were permethrin (45 times) and endosulfan ( 34 times) followed by deltamethrin (27 times). The findings of this study pointed to the following recommendations: the need for a monitoring program for pesticide residues in imported food crops.
\end{abstract}

\section{Introduction}

Fresh vegetables are an important part of a healthy diet as they are a significant source of vitamins and minerals. However, fresh vegetables can also be a source of noxious toxic substances-pesticides. Vegetables are traded worldwide and the list of pesticides that might have been applied in their agricultural production is usually not known [1-3].

Pesticides constitute a very important group of chemical compounds that have to be controlled due to their high toxicity and their widespread use in agricultural practice for field and postharvest protection. The presence of pesticide residues in food is a direct result of pesticide use on crops. Over 1000 compounds may be applied to agricultural crops in order to control undesirable moulds, insects, and weeds [4]. The pesticide residues causing food contamination have become increasingly frequent in recent years raising question about their human health and economic consequences [5]. Widespread contamination of water, air, and soil by chemicals and industrial pollutants means that the crops that we grow and the animals we use for food are often exposed to toxic substances [6].

The levels of pesticide residues in foodstuffs are generally legislated so as to minimize the exposure of the consumer to harmful or unnecessary intakes of pesticides, to ensure the proper use of pesticides in terms of granted authorization and registration (application rates and preharvested intervals), and to permit the free circulation of pesticide-treated products, as long as they comply with the fixed maximum residue limits (MRLs). MRL for pesticide residues represents the maximum concentration of that residue (expressed in $\mathrm{mg} / \mathrm{kg}$ ) that is legally permitted in specific food items. The establishment of MRL is based on good agricultural practice 
data on food derived from commodities. MRLs are not toxicological limits, but they must be toxicologically acceptable. Exceeded MRLs are strong indicators of violations of good agricultural practices [7-9].

A multiresidue method is described for determination of 86 pesticides commonly used in crop protection. Good sensitivity and selectivity of the method are obtained with limits of quantification $0.01 \mathrm{mg} / \mathrm{kg}$ in almost all cases. The method was applied very satisfactorily to routine analysis as a complement to traditional GC-MS method and finally, limit of detection was also 10-20 times lower than maximum residue levels (MRL) established by codex alimentarius commission. More than 500 samples from leafy vegetables have been collected from vegetables market (Riyadh Development Company) in Riyadh. Pesticide residues were detected in $24.69 \%$ of the total samples (140 from 567 samples) and pesticides concentration was higher than MRL in 104 samples [10].

The objective of this study was to investigate the presence of pesticide residues in nonleafy vegetables in food market in Saudi Arabia. Samples were collected from the central market located in Riyadh (Al-Tamer Vegetables Market), during two years, that is, 2007-2008. Collected data are to be used as a reference point for future monitoring and taking preventive measures to minimize human health risks.

\section{Materials and Method}

2.1. Reagents and Equipments. All pesticide standards were obtained from (Riedel de Haen and Supelco). We prepared $1 \mathrm{mg} / \mathrm{mL}$ stock solution of each by dissolving $20 \mathrm{mg}$ of the pure analytical standard in $20 \mathrm{~mL}$ of acetone. A single composite standard solution was prepared by diluting with acetone according to limit of detection (LOD). All standard solutions were stored in glass-stoppered flasks at $4^{\circ} \mathrm{C}$. Mixed compound calibration solutions were prepared in acetone and they were used as spiking solution. Solvents (residue analysis grade) used were acetone, acetonitrile, petroleum ether, and other reagents such as sodium chloride and anhydrous sodium sulphate; florisil 60-100 mesh for residue analysis was also purchased from (Fluka). The florisil (activated magnesium silicate used as adsorbent) and anhydrous sodium sulphate were activated at $100^{\circ} \mathrm{C}$ over night and stored in $500 \mathrm{~mL}$ glass flask with glass stoppers and stored in oven at $100^{\circ} \mathrm{C}$. The equipments used included a high-speed blender with a stainless steel jar (waring, USA), a shaking separation final (GFL, Germany), a rotary evaporator, R 215 and cooler circulator chiller B-740 (Buchi, Switzerland), Buchner funnel and chromatographic tubes with Teflon stopcocks and course fritted glass (Agilent, USA), and syringes (Hamilton Bonadus AG, Switzerland). All glassware were rinsed thoroughly using soap and deionization water, then washed with acetone and dried in oven $\left(100-130^{\circ} \mathrm{C}\right)$ over night

2.2. Samples Collection. This study was conducted during two years from January 2007 to December 2008. More than 500 nonleafy vegetable samples (cold pepper, egg plant, carrot, cucumber, potato, hot pepper, cultivation tomato, squash, beans, okra, onions, cauliflower, and green house tomato) have been collected from Al-Tamer Vegetables Market in Riyadh, Saudi Arabia. Samples were put in sterile polythene bags and transported to the laboratory where they were analyzed immediately or stored at $4^{\circ} \mathrm{C}$ until analysis within $24 \mathrm{~h}$.

2.3. Sample Preparation, Extraction, and Partitioning. The chopped samples of raw nonleafy vegetable (120 g) were placed in a stainless steel jar 1L and extracted with $200 \mathrm{~mL}$ of acetonitrile and $10 \mathrm{~g}$ celite, the blender was vigorously homogenized into high speed for $2 \mathrm{~min}$, and the mixture was filtrated by using Buchner funnel fitted with shark-skin filter paper into $500 \mathrm{~mL}$ suction flask (Buchi, Switzerland). An aliquot of organic was transferred to $1 \mathrm{~L}$ separator funnel and added $100 \mathrm{~mL}$ of petroleum ether (PE) and the mixture was vigorously shaken for 1-2 min and then was added $100 \mathrm{ml}$ saturated solution of $\mathrm{NaCl}$ and 600 water. The mixture was vigorously mixed and the separator funnel was allowed to be held at horizontal position for few minutes. The aqueous layer was discarded and the solvent layer was washed with twice time $100 \mathrm{~mL}$ portions of distilled water and the washed layer was transferred into $100 \mathrm{~mL}$ beaker and washed with $15 \mathrm{~g}$ of anhydrous sodium sulphate. Finally, the extract was concentrated to $5 \mathrm{~mL}$ volume and transferred directly to florisil column $(n=3)$.

2.4. Minimum Detection Limit (MDL). To determine the maximum residue limits (MRL), retention time (Rt), limit of quantification (LOQ), ion target, qualifier ions $m / z$ by scan mode, and perform the GC-MS quantification (Table 1) by using a four-point calibration curve plotting peak area versus $\mathrm{mg} \mathrm{l}^{-1}$ concentration of 86 pesticides using the dilution levels ranged from 0.0001 to $5.00 \mathrm{mg} \mathrm{l}^{-1}$.

2.5. Florisil Column Cleanup. Florisil column cleanup was conducted according to the AOAC [11]. The column was peppered containing about $12 \mathrm{~cm}$ activated florisil topped with $1 \mathrm{~cm}$ anhydrous sodium sulphate, and column was washed by $40 \mathrm{~mL}$ petroleum ether (PE) and was added extract concentrated to $5 \mathrm{~mL}$ and was allowed to pass through the column. The walls of the tube were rinsed additional small portions of petroleum ether and elute at $5 \mathrm{~mL} / \mathrm{min}$ with $200 \mathrm{~mL}$ 6\% eluting solvent (diethyl ether in petroleum ether)

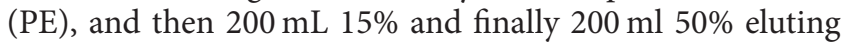
solvent (diethyl ether in $\mathrm{PE}$ ) at $5 \mathrm{~mL} / \mathrm{min}$.

2.6. Chromatographic Instrumentation and Quantification. Gas chromatograph-mass spectrometer (Aglient model $6890 \mathrm{~N}$ ) gas chromatograph coupled with (model 5975B) quadrupole mass spectrometer with a GC column HP-5MS $5 \%$ phenyl and $95 \%$ methyl siloxane, $30 \mathrm{~m} \times 0.25 \mathrm{~mm}$ id $\times$ $0.25 \mu \mathrm{m}$ film thickness. GC operating conditions: splitless injection, injector temperature $250^{\circ} \mathrm{C}$, helium carrier gas (99.9999 purity) at flow rate $0.9 \mathrm{~mL} / \mathrm{min}$ with column head pressure $7.4 \mathrm{psi}$, oven temperature from $70^{\circ} \mathrm{C}$ ( 2 min hold), then raised to $130^{\circ} \mathrm{C}$ at the rate $\left(25^{\circ} \mathrm{C} / \mathrm{min}\right)$ afterwards raised to $220^{\circ} \mathrm{C}$ at $\left(2^{\circ} \mathrm{C} / \mathrm{min}\right)$ and then raised to $280^{\circ} \mathrm{C}$ at $\left(10^{\circ} \mathrm{C} / \mathrm{min}\right)$ and eventually $(4.6 \mathrm{~min}$ hold $)$. The sample $(1 \mu \mathrm{L})$ was injected in split less modes. The MS system was 
TABle 1: Parameter of retention time, LOQ, target, and qualifier ions $m / z$ by scan mode.

\begin{tabular}{|c|c|c|c|c|c|c|}
\hline \multirow{2}{*}{ Number } & \multirow{2}{*}{ Compounds } & \multirow{2}{*}{ Retention time min } & \multirow{2}{*}{ LOQ } & \multirow{2}{*}{ Target ion $\mathrm{m} / \mathrm{z}$} & \multicolumn{2}{|c|}{ Qualifier ions $m / z$} \\
\hline & & & & & $Q_{1}$ & $Q_{2}$ \\
\hline 1 & Dichlorvos & 7.211 & 0.02 & 109 & 185 & 79 \\
\hline 2 & Propamocarb & 9.849 & 0.04 & 58 & 71 & 129 \\
\hline 3 & Mevinphos & 10.828 & 0.09 & 127 & 192 & 109 \\
\hline 4 & Chloroneb & 13.015 & 0.01 & 191 & 193 & 206 \\
\hline 5 & Methomyl & 14.837 & 0.10 & 105 & 88 & 57 \\
\hline 6 & Propachlor & 16.350 & 0.02 & 120 & 77 & 176 \\
\hline 7 & Propoxur & 16.440 & 0.03 & 110 & 152 & 81 \\
\hline 8 & Ethoprophos & 17.183 & 0.05 & 157 & 97 & 139 \\
\hline 9 & Bendiocarb & 18.808 & 0.01 & 151 & 126 & 166 \\
\hline 10 & Sulfotep & 19.350 & 0.01 & 322 & 202 & 97 \\
\hline 11 & Alfa-BHC & 19.449 & 0.02 & 183 & 181 & 219 \\
\hline 12 & Hexachlorobenzene & 19.949 & 0.05 & 284 & 249 & 142 \\
\hline 13 & Dichloran & 20.412 & 0.03 & 176 & 206 & 124 \\
\hline 14 & Dimethoate & 20.694 & 0.02 & 87 & 93 & 125 \\
\hline 15 & Simazine & 21.240 & 0.01 & 201 & 186 & 173.2 \\
\hline 16 & Carbofuran & 21.517 & 0.01 & 164 & 149 & 123 \\
\hline 17 & Lindane & 21.953 & 0.01 & 219 & 181 & 111 \\
\hline 18 & Fonofos & 22.837 & 0.06 & 109 & 137 & 246 \\
\hline 19 & Delta-BHC & 23.934 & 0.05 & 181 & 219 & 111 \\
\hline 20 & Diazinon & 24.181 & 0.03 & 179 & 137 & 152 \\
\hline 21 & Iprobenfos & 25.472 & 0.04 & 91 & 204 & 122 \\
\hline 22 & Pirimicarb & 26.194 & 0.05 & 166 & 72 & 238 \\
\hline 23 & Dichlofenthion & 26.869 & 0.01 & 279 & 223 & 162 \\
\hline 24 & Phosphamidon I & 27.074 & 0.03 & 127 & 72 & 264 \\
\hline 25 & Phosphamidon II & 27.105 & 0.05 & 127 & 72 & 264 \\
\hline 26 & Chlorpyrifos-Me & 27.530 & 0.03 & 286 & 125 & 288 \\
\hline 27 & Vinclozolin & 27.643 & 0.02 & 212 & 285 & 187 \\
\hline 28 & Carbaryl & 27.846 & 0.03 & 144 & 115 & 116 \\
\hline 29 & Alachlor & 28.292 & 0.04 & 160 & 188 & 146 \\
\hline 30 & Ronnal & 28.738 & 0.02 & 285 & 287 & 125 \\
\hline 31 & Metalaxyl & 28.894 & 0.05 & 206 & 146 & 192.2 \\
\hline 32 & Fenitrothion & 30.004 & 0.07 & 277 & 125 & 109 \\
\hline 33 & Linuron & 30.118 & 0.04 & 61 & 187 & 124 \\
\hline 34 & Aldrin & 30.417 & 0.02 & 66 & 263 & 91 \\
\hline 35 & Thiobencarb & 30.794 & 0.08 & 100 & 72 & 125 \\
\hline 36 & Malathion & 31.310 & 0.03 & 127 & 173 & 99 \\
\hline 37 & Fenthion & 31.679 & 0.03 & 278 & 125 & 109 \\
\hline 38 & Pirimiphos-ethyl & 34.279 & 0.05 & 318 & 333 & 304 \\
\hline 39 & Captan & 34.791 & 0.06 & 79 & 151 & 114 \\
\hline 40 & Chlorfenvenphos & 35.549 & 0.02 & 267 & 323 & 269 \\
\hline 41 & Chlordane-trans & 35.990 & 0.04 & 373 & 375 & 237 \\
\hline 42 & Alfa-endosulfan & 36.919 & 0.09 & 239 & 237 & 195 \\
\hline 43 & Nanchlor-trans & 37.168 & 0.01 & 409 & 100 & 237 \\
\hline 44 & Chlordane-cis & 37.311 & 0.05 & 375 & 373 & 377 \\
\hline 45 & Disulfoton sulfone & 37.670 & 0.03 & 213 & 153 & 97 \\
\hline 46 & Dieldrin & 39.172 & 0.02 & 79 & 265 & 81 \\
\hline 47 & P,P-DDE & 39.688 & 0.01 & 246 & 318 & 248 \\
\hline 48 & O,P-DDD & 40.321 & 0.01 & 235 & 237 & 165 \\
\hline 49 & Endrin & 40.920 & 0.02 & 263 & 265 & 281 \\
\hline 50 & Beta-endosulfan & 41.820 & 0.03 & 207 & 239 & 195 \\
\hline
\end{tabular}


TABLE 1: Continued.

\begin{tabular}{|c|c|c|c|c|c|c|}
\hline \multirow{2}{*}{ Number } & \multirow{2}{*}{ Compounds } & \multirow{2}{*}{ Retention time min } & \multirow{2}{*}{ LOQ } & \multirow{2}{*}{ Target ion $\mathrm{m} / \mathrm{z}$} & \multicolumn{2}{|c|}{ Qualifier ions $m / z$} \\
\hline & & & & & $Q_{1}$ & $Q_{2}$ \\
\hline 51 & Chlorobenzilate & 42.683 & 0.04 & 251 & 139 & 253 \\
\hline 52 & P,P-DDD & 43.234 & 0.01 & 235 & 237 & 165 \\
\hline 53 & Benodanil & 43.773 & 0.03 & 231 & 323 & 203 \\
\hline 54 & Ethion & 44.131 & 0.01 & 231 & 97 & 153 \\
\hline 55 & Carbophenothion & 45.558 & 0.04 & 157 & 121 & 125 \\
\hline 56 & Resmethrin I & 48.965 & 0.03 & 123 & 171 & 143 \\
\hline 57 & Resmethrin II & 49.532 & 0.03 & 123 & 171 & 143 \\
\hline 58 & Hexabromobenzene & 49.772 & 0.04 & 551 & 554 & 549 \\
\hline 59 & Phosmet & 50.300 & 0.03 & 160 & 161 & 77 \\
\hline 60 & EPN & 50.726 & 0.04 & 157 & 169 & 185 \\
\hline 61 & Dicofol & 50.955 & 0.02 & 139 & 111 & 251 \\
\hline 62 & Fenoxycarb & 51.040 & 0.07 & 255 & 186 & 116 \\
\hline 63 & Tetramethrin II & 51.322 & 0.02 & 164 & 123 & 81 \\
\hline 64 & Tetradifon & 52.029 & 0.05 & 159 & 111 & 229 \\
\hline 65 & Mirex & 52.460 & 0.01 & 272 & 274 & 270 \\
\hline 66 & Furathiocarb & 52.620 & 0.04 & 163 & 57 & 164 \\
\hline 67 & Amitraz & 53.373 & 0.03 & 132 & 121 & 147 \\
\hline 68 & Lambda-cyhalothrin & 53.770 & 0.05 & 181 & 197 & 208 \\
\hline 69 & Azenophos-ethyl & 53.882 & 0.03 & 132 & 160 & 77 \\
\hline 70 & Allethrin I & 54.515 & 0.04 & 123 & 181 & 81 \\
\hline 71 & Allethrin II & 54.523 & 0.04 & 123 & 181 & 81 \\
\hline 72 & Allethrin III & 54.590 & 0.04 & 123 & 181 & 81 \\
\hline 73 & Permethrin I & 54.891 & 0.02 & 183 & 163 & 165 \\
\hline 74 & Permethrin II & 55.111 & 0.02 & 183 & 163 & 165 \\
\hline 75 & Coumaphos & 55.165 & 0.02 & 263 & 226 & 109 \\
\hline 76 & Cyfluthrin III & 55.855 & 0.05 & 163 & 165 & 226 \\
\hline 77 & Cyfluthrin I & 55.997 & 0.04 & 163 & 165 & 226 \\
\hline 78 & Cyfluthrin IV & 56.103 & 0.04 & 163 & 165 & 226 \\
\hline 79 & Cyfluthrin II & 56.162 & 0.04 & 163 & 165 & 226 \\
\hline 80 & Cypermethrin II & 56.284 & 0.03 & 163 & 165 & 181 \\
\hline 81 & Cypermethrin IV & 56.424 & 0.03 & 163 & 165 & 181 \\
\hline 82 & Cypermethrin I & 56.522 & 0.03 & 163 & 165 & 181 \\
\hline 83 & Cypermethrin III & 56.575 & 0.03 & 163 & 165 & 181 \\
\hline 84 & Fenvalerate I & 57.454 & 0.05 & 125 & 167 & 281 \\
\hline 85 & Fenvalerate II & 57.716 & 0.03 & 125 & 167 & 281 \\
\hline 86 & Deltamethrin & 58.440 & 0.02 & 253 & 181 & 281 \\
\hline
\end{tabular}

routinely set in selective ion monitoring (SIM) mode and each compound was quantitated based on peak area using one target and one or two qualifier ion. Mass spectrometer parameter was set as follows: electron impact ionization mode with $70 \mathrm{eV}$ electron energy and scan mass range $100-400$ at $0.62 \mathrm{sec} / \mathrm{cycle}$. Ion source temperature $230^{\circ} \mathrm{C}$, MS quad temperature $150^{\circ} \mathrm{C}$, EM voltage 1450 , and solvent delay 4 in.

\section{Results and Discussion}

A multiresidue procedure was carried out to monitor the pesticide residues in a wide range of the most common consumed non leafy vegetables samples collected during two years, that is, 2007-2008. The analyzed samples composed of thirteen species of non leafy vegetables, that is, hot pepper, bell pepper, onions, potato, cucumber, okra, bean, carrot, cultivation tomato, green house tomato, squash, egg plant, 
and cauliflower. A wide range of pesticide residues were detected and quantified in the analyzed samples during the two years of this study. In 2007, it was detected the residues of 31 pesticides while in 2008 it was detected the residues of 28 pesticides.

3.1. Pesticide Residues in Nonleafy Vegetables during the Year of 2007. Data in Table (2) shows the amounts of the detected pesticide residues in non leafy vegetable samples from different farms and locations collected from Al-tamer vegetables market in Riyadh, Saudi Arabia during the year of 2007. According to the detected pesticides, it is clear that there are a wide range of compounds which included insecticides (31 compounds), herbicides (four compounds, that is, linuron, simazine, alachlor, and aldrin), and fungicides (one compound, that is, tetradifon). The detected insecticide residues which represent the majority of the detected compounds, it was found that such insecticides could be classified chemically into their major four chemical groups, that is, organochlorines, organophosphorus, pyrethroids, and carbamates. The detected organochlorines substances were six insecticides, that is, chloroneb, lindane, endosulfan, dicloran, mirex, and P,P-DDD while the organophosphorus insecticides included nine agents, that is, chlorpyrifos, dimethoate, malathion, mevinphos, disulfoton, phosmet, ethoprophos, diazinon and iprobenfos. As for pyrethroids, it was detected of seven compounds included permethrin, deltamethrin, cypermethrin, $\lambda$-cyhalothrin, cyfluthrin, fenvalerate, and resmethrin. For carbamates, only three compounds were detected, that is, carbaryl, bendiocarb, and thiobencarb. The mentioned pesticides were detected in thirteen non leafy vegetables, included hot pepper, cold pepper, onions, potato, cucumber, okra, bean, carrot, and cultivation tomato, green house tomato, squash, egg plant, cauliflower.

According to the detected pesticides in and/or on the non leafy vegetables (Table 2) involved in this study, it was observed that total numbers of the detected compounds were found in cold pepper followed by cucumber, hot pepper, potato, okra, bean, carrot, squash, egg plant, cultivation tomato, green house tomato, onions, and cauliflower. The total number of the detected compounds in such leafy vegetables in this study was $10,9,8,8,8,8,8,7,7,5,4,3$, and 1 compound, respectively.

The data tabulated in Table 2 also showed the detected amounts of pesticide residues in non leafy vegetables could be ranked in descending order as follows: cold pepper, egg plant, carrot, cucumber, potato, hot pepper, cultivation tomato, squash, bean, okra, onions, cauliflower, and green house tomato which represent the lower non leafy vegetable contained pesticide residues. In terms of figures, the sum of the detected pesticide residues in such non leafy vegetables were $1.507,0.457,0.302,0.296,0.293,0.264,0.239,0.186$, $0.163,0.089,0.0654,0.062$, and $0.05 \mathrm{ppm}$, respectively. From such ranking, it was observed that cold pepper, egg plant, and carrot were the most contaminated non leafy vegetables.

The frequency of the detected pesticide residues was calculated in the analyzed non leafy vegetables, it was found that the most frequent compounds was permethrin followed by deltamethrin and linden, endosulfan, chlordane, linuron, dimethoate, phosmet, and carbaryl. In terms of figures, the frequencies for these pesticides were 11, 8, 6, 5, 5, 5, 4, and 4, respectively. The other detected compounds were frequented from three to one time. From the presented results it could conclude that cold pepper, egg plant, and carrot were the most contaminated non leafy vegetables, and the pyrethroids are the most frequented pesticides during the year of 2007.

3.2. Pesticide Residues in Leafy Vegetables during 2008. In the agriculture season of 2008, data represented the detected amounts of pesticide residues in non leafy vegetables collected during the season of 2008 are listed in Table 3. According to the detected amounts and/or compounds, it was observed that the pattern of the detected pesticide residues in the collected non leafy vegetable samples were slightly differed from those presented in 2007 season. For example, in 2008 season, it was found the chloroneb, lindane, endosulfan, dicloran, and P,P-DDD as organochlorine compound, diazinon, phosphamidon, sulfotep, dimethoate, and mevinphos as organophosphorus, cypermethrin, deltamethrin, cyfluthrin, permethrin, resmethrin, tetramethrin, lambda cyhlothrin, and fenvalerate as pyrethroids. Also, it was detected propoxur, carbofuran, propamocarb, and bendiocarb as carbamates insecticides. As for fungicides, it found benomyl, tetradifon, and chlorobenzilate. As for the detected amounts, it is clear that cypermethrin represented the highest amounts of the detected residues which ranged between 0.086 and $0.762 \mathrm{ppm}$ while the other detected concentrations were ranged between 0.077 and $0.0003 \mathrm{ppm}$. Overall, the pesticide residues which were found in this study were approximatly similar to other studies [12-14].

In addition, based on the number of detected residues, in non leafy samples, could be ranked in descending order as follow cucumber, cold pepper, potato, onions, okra, green house tomato, egg plant, bean, squash, hot pepper, cultivation tomato, cauliflower, and carrot. The detected number of compound residues was 12.0, 9.0, 9.0, 8.0, 7.0, 7.0, 7.0, 6.0, $6.0,5.0,4.0,4.0$, and 3.0, respectively. As for the detected amounts of the mentioned pesticides, the ranking of non leafy samples becomes different to be egg plant is the most contaminated leafy samples followed by green house tomato $<$ cold pepper $<$ okra $<$ cucumber $<$ onions $<$ cauliflower $<$ carrot $<$ potato $<$ bean $<$ squash $<$ hot pepper $<$ cultivation tomato. In terms of figures, the total detected amounts are $1.041,0.849,0.833,0.694,0.485,0.344,0.308,0.298$, $0.298,0.216,0.193,0.183$, and $0.057 \mathrm{ppm}$, for the mentioned leafy samples, respectively. In case of the frequencies of pesticide residues between the collected vegetables samples, it was observed that cypermethrin was the most frequented compound followed by endosulfan followed by dicloran and chlorobenzilate in which their frequencies were 7.0, 6.0, 5.0, and 5.0, respectively. The other detected compounds were frequented from four to one time. However, the presented data of 2008 season clearly shows that egg plant samples were the most contaminated non leafy vegetables followed by cold pepper, okra, and cucumber while hot pepper and cultivation tomato were the lowest contaminated vegetable samples. Data was mentioned previously partially in agreement with $[15,16]$. 


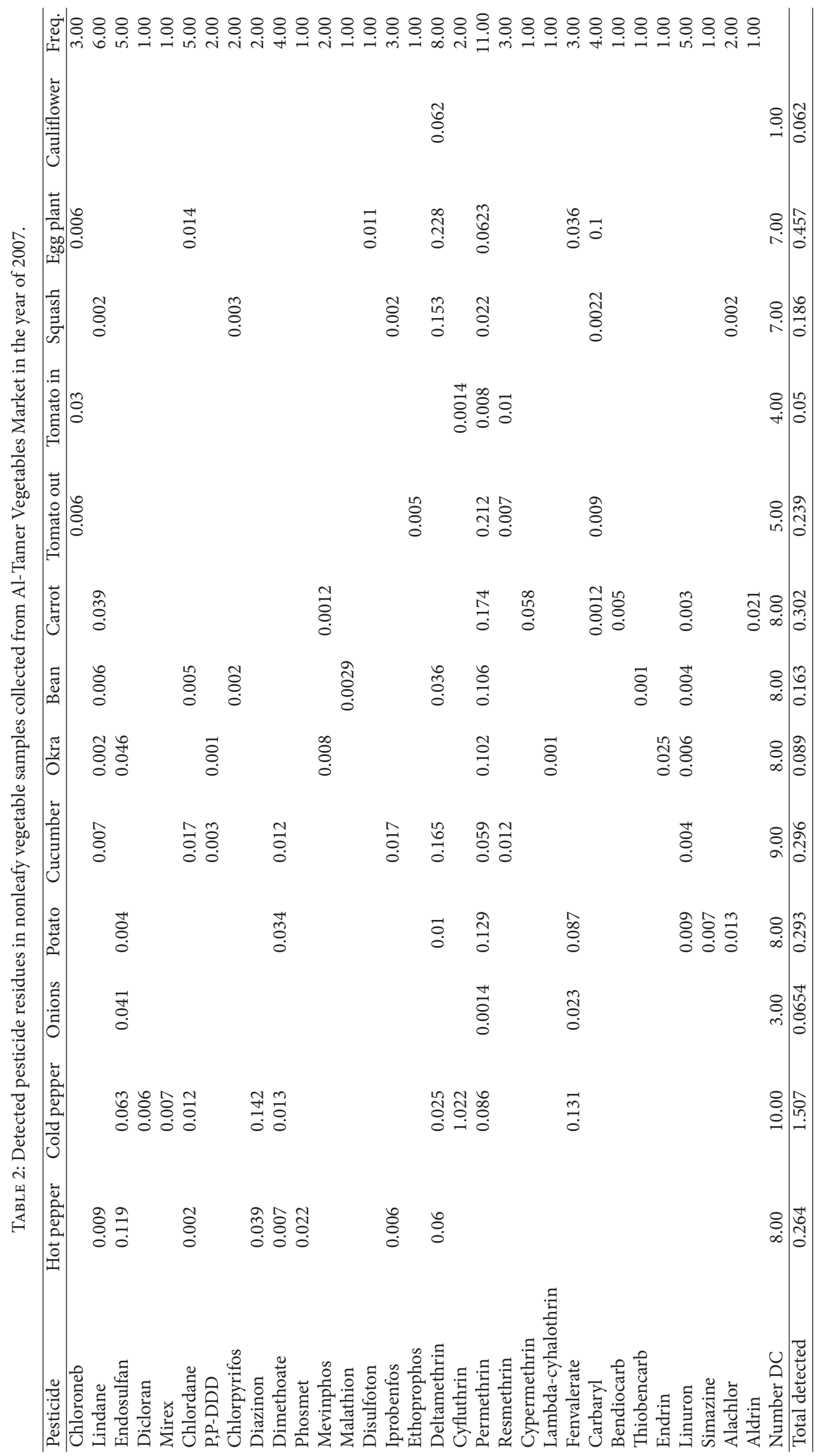




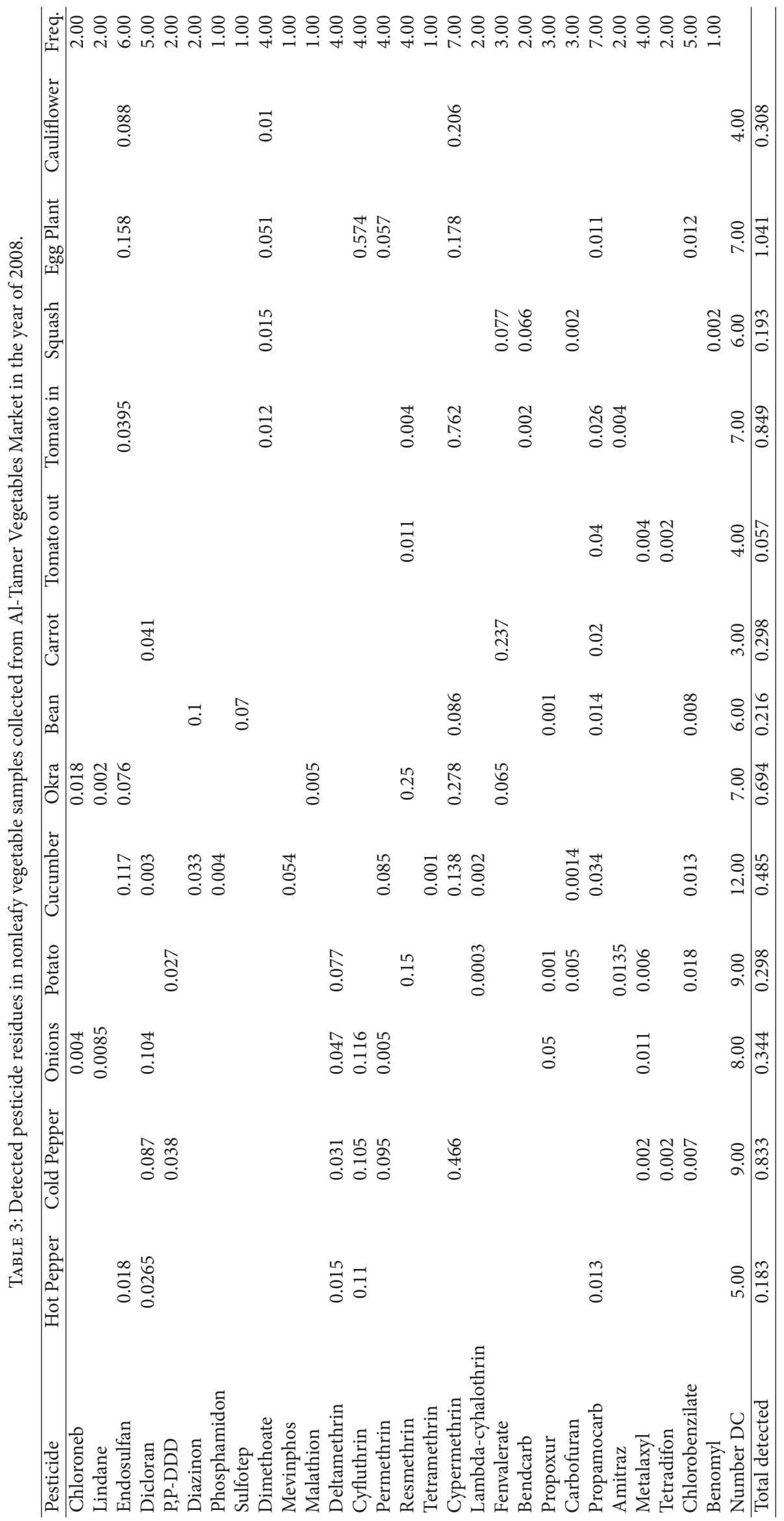




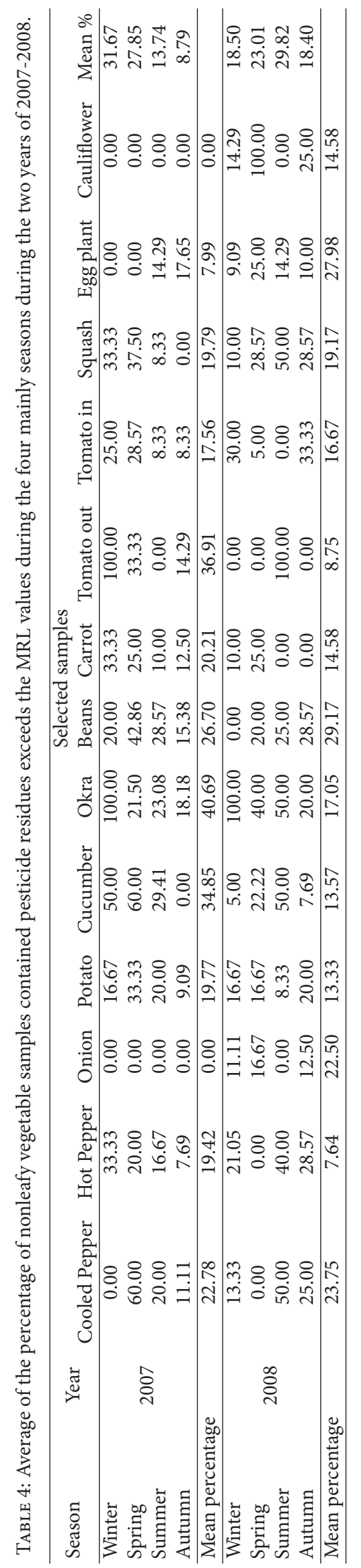


The detected amounts of pesticide residues during the two mentioned seasons, that is, 2007/20008, were compared with that MRL values; it could calculate the average of percentage of non leafy vegetable samples contained amounts of residues exceeds the MRL values as listed in Table 4. From such data, it is clear that the majority of the analyzed vegetable samples collected in 2007 contained exhibited higher values than those of 2008 except five non leafy vegetables, that is, cold pepper, onions, beans, egg plant, and cauliflower which were higher in their values than those of 2007. In addition, when the analyzed samples distributed between the four mainly seasons of each year, that is, winter, spring, summer, and autumn (based on the analyzed date), neither correlation nor trend could be observed between the pesticide residues content and the mentioned season. The selected plant foods will not give a for adverse biological effects to take place providing the residues of pesticides are controlled to be kept to a minimum. Pesticides residue monitoring programs should then be implemented to assure the minimum allowable residue levels in plant foods, especially with regards to permethrin, endosulfan, and deltamethrin [17].

The results of the detected amounts of pesticide residues in the selected vegetable, it is therefore clear that patterns of pesticide use are crop dependent: the predominant use of pesticides in vegetables is mainly to control a wide range of pests. In addition, the obtained results clearly indicate the actual situation of the misuse of insecticides which may affect in turn at long period the consumers health, and the most reasonable explanation for the highly detected pesticide residues in cold pepper, egg plant, and carrot may be due to the intensive use of insecticides and the highly deposited amounte of the applied compounds on the broad leafs of such vegetables. Overall, insecticides found in this study were similar to those found in other studies $[12,13,18-21]$.

\section{Conclusion}

However, the detected amounts of the mentioned insecticides in these important non leafy vegetables make the necessary to continue the pesticide residue monitoring programs which must be implemented to assure the minimum allowable residue levels in plant foods. With the LLC and GCMS multiresidue method, the optimum conditions were met to extract and determined 86 pesticides in more than 1057 vegetable samples less time and low detection limit $(0.001 \mathrm{ppm})$. The samples no residues and contained pesticide residues at or below MRL were detected in $83.90 \%$. Meanwhile, the detected pesticides concentration had exceeded the MRL in $15.89 \%$ of the total tested samples.

\section{Acknowledgment}

This project was supported by King Saud University, Deanship of Scientific Research and College of Food and Agriculture Sciences Research Center.

\section{References}

[1] M. H. El-Saeid, New techniques for residue analysis of pesticides in foods [Ph.D. thesis], Texas Southern University;
Al-Azhar University, Faculty of Agriculture, Cairo, Egypt, 1999.

[2] H. J. Stan, "Pesticide residue analysis in foodstuffs applying capillary gas chromatography with mass spectrometric detection - State-of-the-art use of modified DFG-multimethod S19 and automated data evaluation," Journal of Chromatography A, vol. 892, no. 1-2, pp. 347-377, 2000.

[3] M. Okihashi, Y. Kitagawa, K. Akutsu, H. Obana, and Y. Tanaka, "Rapid method for the determination of 180 pesticide residues in foods by gas chromatography/mass spectrometry and flame photometric detection," Journal of Pesticide Science, vol. 30, no. 4, pp. 368-377, 2005.

[4] D. Ortelli, P. Edder, and C. Corvi, "Multiresidue analysis of 74 pesticides in fruits and vegetables by liquid chromatographyelectrospray-tandem mass spectrometry," Analytica Chimica Acta, vol. 520, no. 1-2, pp. 33-45, 2004.

[5] M. E. Smith, E. O. van Ravenswaay, and R. S. Thompson, "Sales loss determination in food contamination incidents: an application to milk bans in Hawaii," American Journal of Agricultural Economics, vol. 70, no. 3, pp. 513-520, 1998.

[6] UNEP/GEMS, The Contamination of Food, UNEP, Nairobi, Kenya, 1992.

[7] L. Nasreddine and D. Parent-Massin, "Food contamination by metals and pesticides in the European Union. Should we worry?" Toxicology Letters, vol. 127, no. 1-3, pp. 29-41, 2002.

[8] M. H. El-Saeid, "Pesticide residues in canned foods, fruits, and vegetables: the application of Supercritical Fluid Extraction and chromatographic techniques in the analysis," The Scientific World Journal, vol. 3, pp. 1314-1326, 2003.

[9] EL-Saeid H. M. and H. Khan, "Analysis of pesticides in food samples by supercritical fluid chromatography," in Handbook of Pesticides, chapter 5, pp. 93-113, Taylor \& Francis; CRC Press, Boca Raton, Fla, USA, 2010.

[10] M. T. Selim, M. H. EL-Saeid, and I. M. Al-Dossari, "Multiresidues analysis of pesticides using gas chromatography mass spectrometry: I- leafy vegetables," Research Journal of Environmental Sciences, vol. 5, no. 3, pp. 248-258.

[11] AOAC, "Pesticide and industrial chemical residues," in Official Methods of Analysis of Association of Official Analytical Chemists, P. E. Corneliussen, Ed., chapter 10, 1995.

[12] S. M. Dogheim, E. M. M. Ashraf, S. A. G. Alla, M. A. Khorshid, and S. M. Fahmy, "Pesticides and heavy metals levels in Egyptian leafy vegetables and some aromatic medicinal plants," Food Additives and Contaminants, vol. 21, no. 4, pp. 323-330, 2004.

[13] P. Amoah, P. Drechsel, R. C. Abaidoo, and W. J. Ntow, "Pesticide and pathogen contamination of vegetables in Ghana's urban markets," Archives of Environmental Contamination and Toxicology, vol. 50, no. 1, pp. 1-6, 2006.

[14] R. M. González-Rodríguez, R. Rial-Otero, B. Cancho-Grande, and J. Simal-Gándara, "Determination of 23 pesticide residues in leafy vegetables using gas chromatography-ion trap mass spectrometry and analyte protectants," Journal of Chromatography A, vol. 1196-1197, no. 1-2, pp. 100-109, 2008.

[15] L. J. Qu, H. Zhang, J. H. Zhu, G. S. Yang, and H. Y. Aboul-Enein, "Rapid determination of organophosphorus pesticides in leeks by GC-TQMS," Food Chemistry, vol. 122, no. 1, pp. 327-332, 2010.

[16] K. A. Osman, A. M. Al-Humaid, S. M. Al-Rehiayani, and K. N. Al-Redhaiman, "Monitoring of pesticidesresidues in vegetables marketed in Al-Qassim region, Saudi Arabia," Ecotoxicology and Environmental Safety, vol. 73, no. 6, pp. 1433-1439, 2010. 
[17] R. Rial-Otero, M. Arias-Estévez, E. López-Periago, B. CanchoGrande, and J. Simal-Gándara, "Variation in concentrations of the fungicides tebuconazole and dichlofluanid following successive applications to greenhouse-grown lettuces," Journal of Agricultural and Food Chemistry, vol. 53, no. 11, pp. 4471-4475, 2005.

[18] Z. H. Zidan, K. A. Mohamed, and A. E. Bayoumi, "Market basket monitoring of pesticides residues on vegetables and fruits kalubia governorate, Egypt," Annals of Agricultural Sciences, vol. 45, no. 2, pp. 743-756, 2000.

[19] P. Cabras and E. Conte, "Pesticide residues in grapes and wine in Italy," Food Additives and Contaminants, vol. 18, no. 10, pp. 880-885, 2001.

[20] M. E. Poulsen and J. H. Andersen, "Results from the monitoring of pesticide residues in fruit and vegetables on the Danish market, 2000-2001," Food Additives and Contaminants, vol. 20, no. 8, pp. 742-757, 2003.

[21] A. B. Gebara, C. H. P. Ciscato, M. D. S. Ferreira, and S. H. Monteiro, "Pesticide residues in vegetables and fruits monitored in São Paulo City, Brazil, 1994-2001," Bulletin of Environmental Contamination and Toxicology, vol. 75, no. 1, pp. 163-169, 2005. 

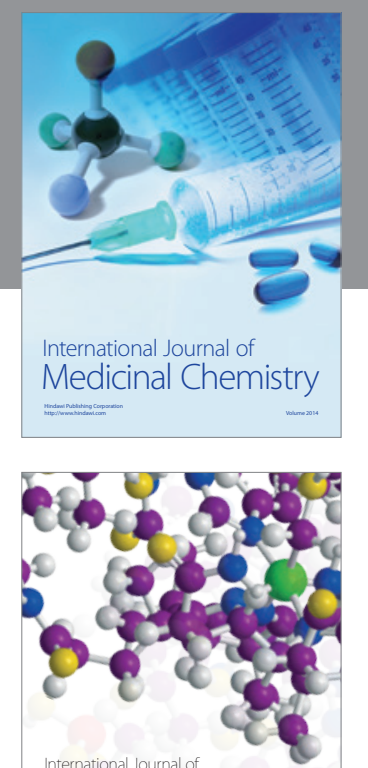

\section{Carbohydrate} Chemistry

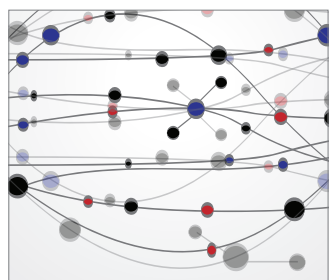

The Scientific World Journal
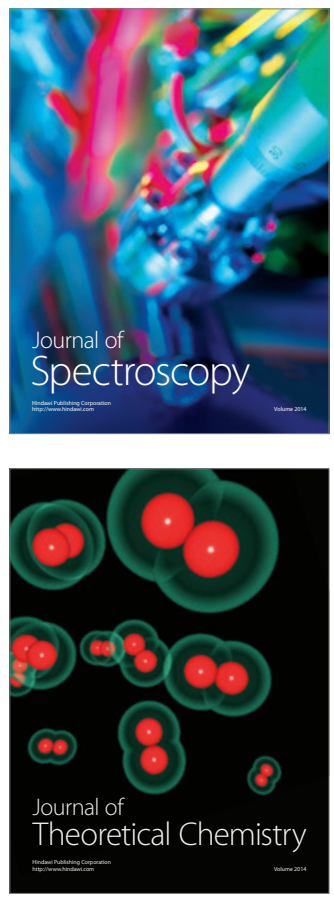
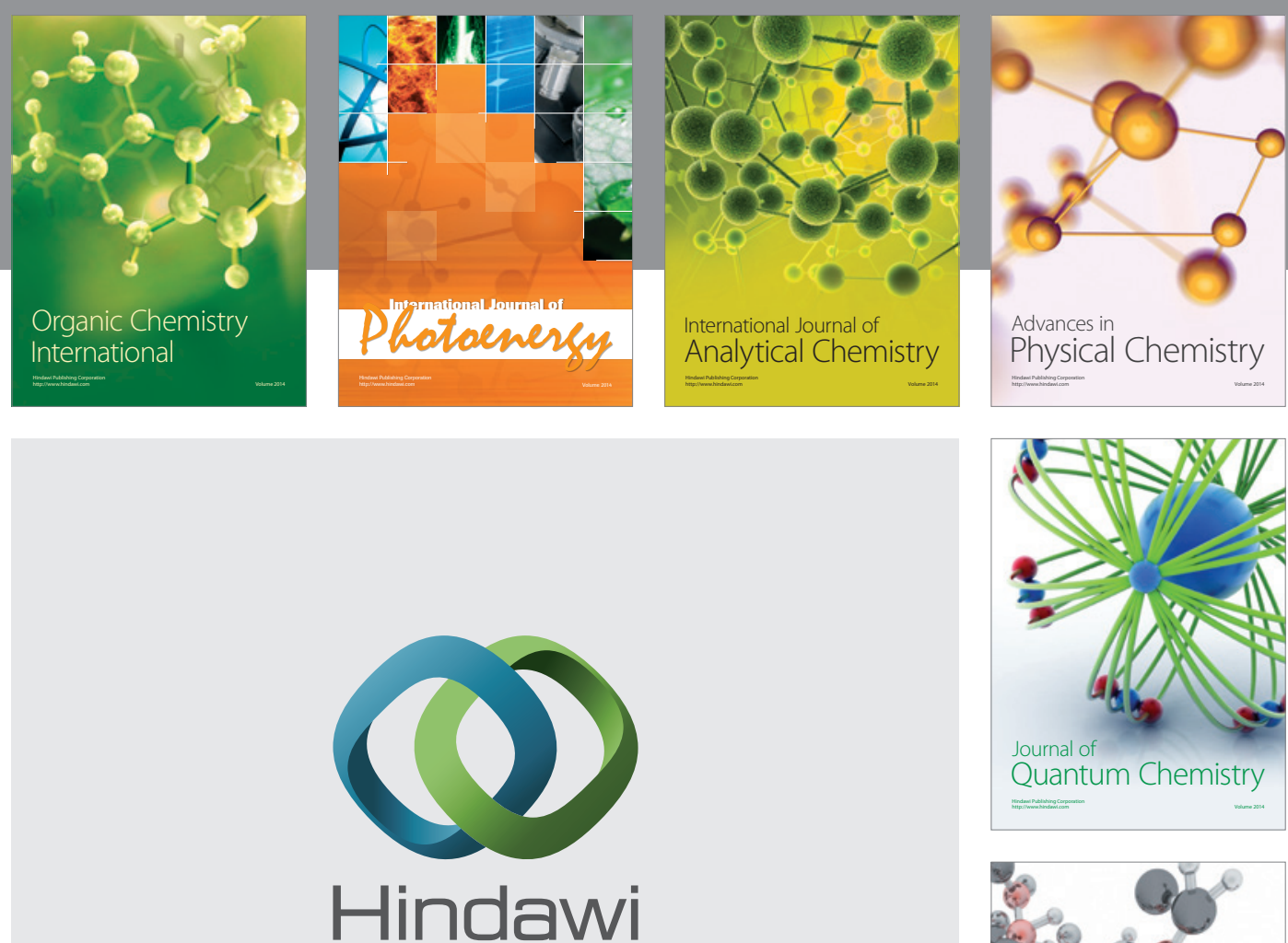

Submit your manuscripts at

http://www.hindawi.com

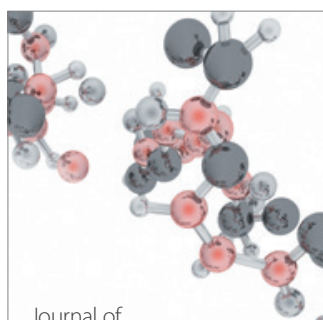

Analytical Methods

in Chemistry

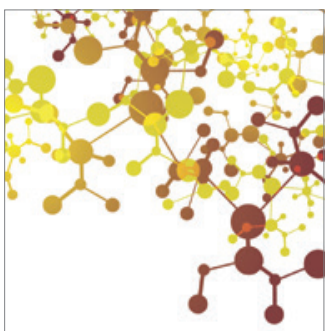

Journal of

Applied Chemistry

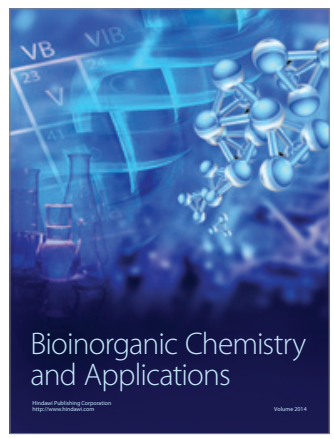

Inorganic Chemistry
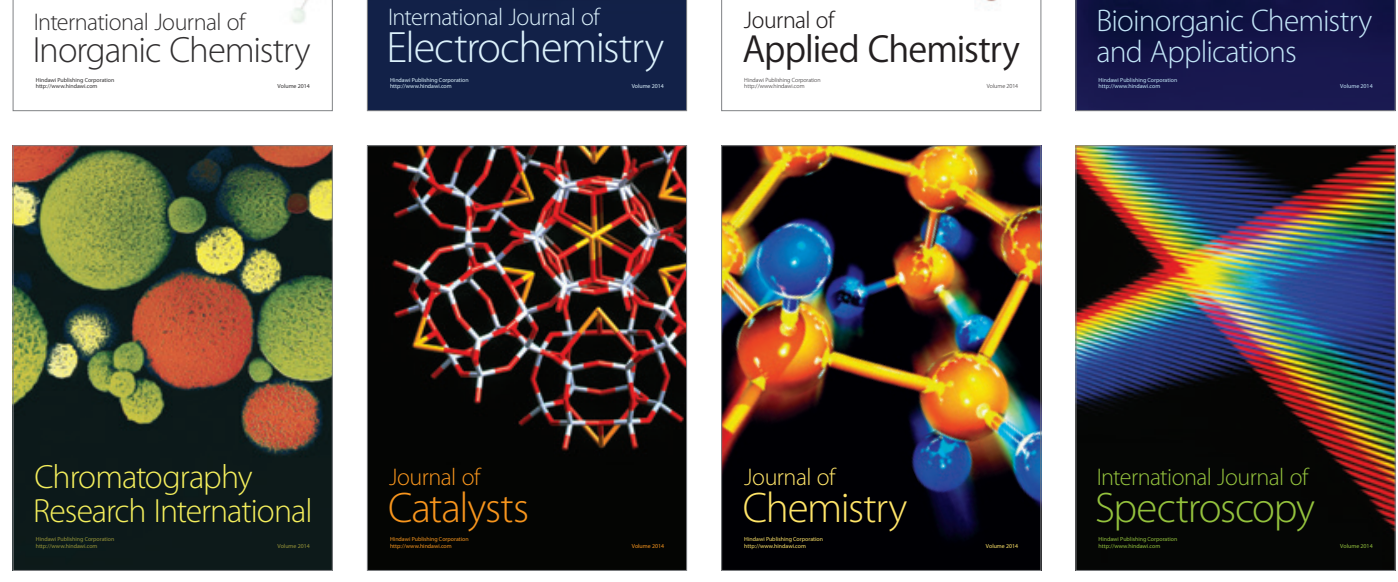